\title{
Ph. Abelin, Les Nouds romanesques chez Stendhal. Empathie et manipulation
}

\section{Michel Arrous}

\section{(2) OpenEdition}

1 Journals

\section{Édition électronique}

URL : http://journals.openedition.org/studifrancesi/10658

DOI : 10.4000/studifrancesi. 10658

ISSN : 2421-5856

Éditeur

Rosenberg \& Sellier

\section{Édition imprimée}

Date de publication : 1 décembre 2017

Pagination : 559-560

ISSN : 0039-2944

\section{Référence électronique}

Michel Arrous, «Ph. Abelin, Les Nœuds romanesques chez Stendhal. Empathie et manipulation », Studi

Francesi [En ligne], 183 (LXI | III) | 2017, mis en ligne le 01 février 2018, consulté le 23 janvier 2021.

URL : http://journals.openedition.org/studifrancesi/10658 ; DOI : https://doi.org/10.4000/

studifrancesi. 10658

Ce document a été généré automatiquement le 23 janvier 2021.

\section{(c) 9 (i) $\Theta$}

Studi Francesi è distribuita con Licenza Creative Commons Attribuzione - Non commerciale - Non opere derivate 4.0 Internazionale. 


\title{
Ph. Abelin, Les Nœuds romanesques chez Stendhal. Empathie et manipulation
}

\author{
Michel Arrous
}

\section{RÉFÉRENCE}

PHILIPPE ABELIN, Les Noeuds romanesques chez Stendhal. Empathie et manipulation, préface de Philippe Berthier, Paris, L'Harmattan, 2017, 437 pp.

1 De Stendhal qui s'est beaucoup préoccupé de soi et de ses rapports avec les autres, on peut assurément dire qu'il s'est livré à l'analyse empathique, aussi Philippe Abelin a-t-il eu raison de contribuer par cette thèse à l'étude des conduites empathiques et de leurs effets dans l'œuvre romanesque de Stendhal. Inspirée de la phénoménologie schelerienne, sa grille de lecture est suffisamment souple pour s'adapter à quelques situations bien choisies mais dont le nombre aurait pu, semble-t-il, être plus important. Plutôt que de disserter sur les concepts ambigus d'empathie et de manipulation, l'auteur propose une définition opérationnelle du comportement des personnages, plus précisément de leur intentionnalité, c'est-à-dire de leur capacité à se mettre à la place d'autrui et, dans les meilleurs cas, à partager ses émotions jusqu'à l'identification dans le processus d'attachement érotique. Quant à la notion de «nœuds romanesques», on comprend qu'elle englobe toutes les relations intersubjectives, aussi bien chez les personnages qui vivent l'empathie sur le mode altruiste (les empathistes-altruistes comme la discrète Théodolinde de Serpierre) que chez ceux qui l'exploitent dans une visée dominatrice. De ces derniers, on trouve chez Stendhal deux belles variétés: le manipulateur empathiste et le manipulateur malfaisant (les happy few du mal); mais il y a aussi des êtres mus par des motivations altruistes et dont l'interventionnisme se résout en une véritable fusion affective. Enfin, Ph. Abelin n'a pas oublié l'empathiste Stendhal qui communique sans cesse avec ses lecteurs. 
2 Le cheminement emprunté permet de passer de l'empathie à l'altruisme, avec ses ambivalences et ses divers avatars, de l'influence à l'exercice du pouvoir, de l'empathie à la "grande passion». C'est négativement qu'est d'emblée exposé le problème de l'empathie avec "San Francesco a Ripa ou le destin d'une société sans empathie» (pp. 37-49): dans cette nouvelle où personne ne se comprend, l'incompréhension conduit à la tragédie. Sont évoquées d'autres faces contrastées de l'empathie avec la figure de l'empathiste-manipulateur, saisie à divers degrés de ses manifestations: d'abord la douce et tendre Louise de Rênal qui possède l'art de diriger son mari («Sans en avoir conscience elle l'avait étudié»), puis le cas évident du grand vicaire Frilair devenu le maître de son maître. Mais l'on sait que cet homme de pouvoir dont le talent est finement décrit lors de son entretien avec Mathilde (pp.58-62) échoue à sauver Julien. Ce n'est pas le cas du chevalier de Bonnivet qui cherche à créer le doute dans l'esprit d'Octave sur la sincérité d'Armance, et qui reste toujours masqué, ni celui du commandeur de Soubirane, bien moins doué (pp. 89-94). L'exemple de L'Abbesse de Castro dont est proposée une double lecture à travers les personnages d'Hélène et de sa mère illustre les ambivalences de l'altruisme (pp.95-126), tandis que ceux du Dr Du Poirier dans Lucien Leuwen et de son confrère Sansfin dans Lamiel illustrent ce que $\mathrm{Ph}$. Abelin appelle l'«altruisme institutionnel» dévoyé par les machinations de ces deux éminents spécialistes de la prise de pouvoir (pp. 127-160). Dans la deuxième partie («De l'influence au pouvoir», pp.193-307), il est question de l'art d'influencer ou du recours à l'empathie dans la manipulation, d'abord repérée dans la pratique du banquier F. Leuwen excellemment vu en «improbable homme d'État», ensuite dans l'aptitude des gouvernants à comprendre et à maîtriser la psychologie du peuple de la principauté de Parme où règne le nihilisme juridique. À leur façon, les héros de Stendhal sont dans le domaine politique des manipulateurs voire de véritables metteurs en scène: Julien a ses modèles (Napoléon, Danton) et Lucien sa stratégie souterraine pour éviter une défaite absolue. En va-t-il de même si l'on considère l'amour dans ce qu'on pourrait appeler sa théâtralité ou sa politique, dans ses rapports avec la manipulation? C'est certes vrai avec les deux relations féminines de Lucien, la comtesse de Vaize et Mme Grandet (pp. 327-350), mais alors il ne s'agit plus de l'amour sentiment absolu ou de cet absolu qu'il découvre avec Mme de Chasteller. Les types de l'empathiste et du manipulateur ou de la manipulatrice sont donc présentés dans leur diversité, même si l'on peut regretter que certains personnages aient été oubliés (F. Cenci) ou trop rapidement évoqués (la Sanseverina, Mosca), et que des aspects de l'empathie aient été négligés (le comique de manipulateurs comme l'apôtre et jésuite Du Poirier, ou Sansfin). On aurait aussi aimé que soit poussée plus avant l'étude de $L a$ Chartreuse de Parme comme roman de l'émotion empathique (pp.167-178). La problématique de l'interventionnisme (par exemple l'empathie valorisée ou l'appel à l'empathie positive dans les interventions du narrateur, technique bien connue depuis Blin et les travaux récents de Marie Parmentier) est aussi mentionnée.

De la spécificité de cette approche, on dira qu'elle est plus convaincante que certaines «relectures» de l'altérité chez Stendhal. À Ph. Abelin qui s'est demandé quelle était la «valeur ajoutée» de sa démarche, on répondra que sa «lecture empathique» est une façon subtile d'entrer en Stendhalie. 